\title{
Workplace Decision-Making in the Trades: Impact of Masculine Attitudes
}

\author{
Leanne Jaeb*†, Evan Parker*, Courtney Black, \\ Karissa Cooper
}

\begin{abstract}
The majority of existing research on gender in the trades focuses on the personal experiences of women working in the trades. As the trades are still male-dominated, the present study investigated tradesmen's adherence to male role norms in relation to workplace safety behaviours and perceptions of co-worker competence. Participants were presented with a vignette that depicted a common, yet potentially unsafe, workplace task in which either a male or female hypothetical coworker was available to assist. Next, participants completed questions pertaining to the safety situation outlined in the vignette. Participants also completed questionnaires of adherence to male role norms, neosexist beliefs, perceptions of their actual male and female co-workers' abilities, and attitudes toward workplace safety. Results indicated that participants showed no gender bias when selecting a hypothetical helper in the situation; rather, adherence to safety protocols appeared to take precedence. Further analysis revealed that for participants assigned to a vignette featuring a hypothetical female coworker, there was a negative correlation between strength of adherence to male role norms and perceptions of actual female co-workers' general workplace abilities. For participants assigned to a vignette featuring a hypothetical male coworker, there was a negative correlation between strength of adherence to male role norms and perceptions of actual coworkers' general safety behaviours on a job site. Possible reasons for these findings, limitations of this study, and future research directions are discussed.
\end{abstract}

Keywords: trades, masculinity, workplace safety, occupational injury, neosexism, gender bias

As a highly gender-segregated field, the trades present an ideal opportunity to examine the impact of masculine attitudes on workplace decision-making. Just over 1.7 million people in Canada ( $9.6 \%$ of the total workforce) were working in the trades in 2015, with men accounting for $81.3 \%$ of employees within the trades (Statistics Canada, 2016). The trades include sectors such as construction, mining, and skilled trades with varying jobs such as electrician, pipefitter, surveyor, carpenter, and labourer (Denissen \& Saguy, 2014; Ericksen \& Schultheiss, 2009).
According to Ness (2012), construction is one of the most gender-segregated sectors and displays strong adherence to traditional gender norms. Some of the literature examining gender segregation in the trades has a male focus (e.g., lacuone, 2005), but most is focused on the female experience; the female experience is typically negative and associated with the prevalence of masculinity within a given workplace (Denissen \& Saguy, 2014; Maclsaac \& Domeme, 2013). Although workplace injuries in Canada have been decreasing since 1987, injuries are still

*Department of Psychology, College of Arts and Science, University of Saskatchewan, Saskatoon, SK, Canada

†Correspondence: leanne.jaeb@usask.ca 
prevalent in male-dominated fields (Government of Canada, 2011), particularly among younger workers (Breslin et al., 2007). This study addresses previous research and addresses the underrepresentation of males in the literature by examining the impact that masculine attitudes and perceptions have on tradesmen in relation to their jobs. The purpose of the study was to determine whether or not attitudes and gender biases in male-dominated fields impact workplace safety decision-making. More specifically, we investigated tradesmen's adherence to male role norms and neosexist beliefs in relation to male help-seeking behaviour, workplace safety behaviours, and perceptions of co-worker competence.

Many occupations in Canada can be categorized into fields that are generally understood to be predominantly male or female. For example, of the Canadians employed in health care and social assistance, the majority (82\%) are female and of those employed in natural resources (e.g., mining, oil and gas), 81\% are male (Statistics Canada, 2016). The gender association and perception of an occupation rests on established gender norms (McDonald, 2013). Gender norms are socially constructed paradigms based on culturally held "values, norms, and ideologies about what it means to be men and women" (Addis \& Mahalik, 2003, p. 7). They prescribe appropriate behaviour for men and women including what type of occupation is socially acceptable (Courtenay, 2000).

According to Reskin and Bielby (2005), the gender stereotyping of occupations is due to the over-reliance on external cues and gender norms. External cues can be as simple as manner of dress or appearance and gender norms dictate what are "appropriate" behaviours and traits for each gender in western society (McDonald, 2013). Expectations of masculinity in the workplace include being logical, assertive, and mechanically inclined, whereas women are assumed to possess qualities that are perceived as feminine, such as being sensitive, caring, and emotionally expressive (McDonald, 2013). Men and women who choose to enter careers contradictory to their ascribed gender blur the boundaries of gender roles. The boundaries of gender roles are suggested and supported by social hierarchies. The term "social hierarchy" refers to one's social standing within a variety of interdependent environments, including family, social, education, and work settings (Berdahl, 2007). Blurring the boundaries of gender roles thereby disrupts the established social hierarchy (Courtenay, 2000).

Challenges to the established social hierarchy by a few employees can contribute to an increase of problematic behaviour such as risk-taking and hostility towards the minority gender (Denissen \& Saguy, 2014). Denissen and Saguy (2014) interviewed 63 American tradeswomen, from various backgrounds, about their experiences working in construction. The authors observed that the presence of tradeswomen jeopardized the self-perceived status and masculinity of tradesmen, disrupting the established social hierarchy. The tradeswomen felt that the open hostility they experienced increased their reluctance to report negative incidents for fear of developing an unfavourable reputation (Denissen \& Saguy, 2014). Ness (2012) interviewed both male and female construction workers in the United Kingdom and found that female workers took more safety risks and worked longer hours in an attempt to prove their competency on the job. The author concluded that the perceived ability of employees on the job site was linked to adherence to traditional masculine attitudes and that masculinity is displayed through "tough work," (e.g., dirty or discomforting physical labour). Overall, women's reports of negative experiences in the trades were largely due to the prevalence of masculine norms. Although Denissen and Saguy (2014) and Ness (2012) focused on the construction industry, their results may also be applicable to other male-dominated trades.

Maclsaac and Domeme (2013) explored women's experiences in the trades using focus groups and determined that differences between training and job site environments resulted in women facing barriers and attempting to "prove themselves" through overworking. While women felt encouraged during general training programs, on-the-job experiences differed. The most prevalent jobsite barrier women faced was the male-centric environment. For example, personal protective equipment was predominantly sized for men, and, more significantly, women received little information on advancement opportunities. Participants suggested that these barriers as well as overworking were a consequence of masculine attitudes about women in the trades.

Neosexism is defined as a "manifestation of a conflict between egalitarian values and residual negative feelings toward women" (Tougas, Brown, Beaton, Joly, 1995, p. 843). Currently, overt sexism is less tolerated in society and has been discouraged from public discourse (Glick \& Fiske, 2001). Sexism has shifted to a covert form in which negative beliefs are subtly expressed (e.g., opposition to affirmative action programs) (Tougas et al., 1995). Employers may unintentionally encourage masculine or neosexist attitudes about women and safety in an effort to retain the "appeal" of working in the trades (Ness, 2012). Low-status labouring jobs are seen as more attractive to men when they are viewed as "masculine" jobs. Succeeding in a masculine job may strengthen a man's identity and increase overall social status for the worker (Ness, 2012).

Embracing safety orientations and policies without addressing masculine attitudes, can enable companies to attribute safety and workplace issues to worker-held masculine attitudes rather than flaws in workplace rules and regulations (Ness, 2012). For large companies employing many contractors, this approach is much simpler when 
compared to equally enforcing and maintaining work safety regulations on all jobsites (Ness, 2012). Addressing workplace safety in the context of masculine attitudes in the trade industries could positively impact occupational health and workplace safety throughout Canada. The latest statistics for occupational injuries in Canada indicate that workplace injury rates have been decreasing since 1987, yet one out of every 68 workers received workers' compensation for injury or harm in 2010 (Government of Canada, 2011). According to statistics from 2008, men consistently show higher rates of injury than women, and construction is the industry with the highest rate of injury, at 24.5 injuries for every 1000 workers (Government of Canada, 2011).

lacuone (2005) interviewed 20 Australian tradesmen and determined that a hierarchy among tradesmen served to reinforce risky behaviours deemed "masculine." Men would engage in risky or life-threatening behaviours in order to maintain their place in, or move up, the masculinecentred hierarchy on the jobsite. Interviewees expressed that the only way to move up the hierarchy was to engage in a dangerous act (e.g., throwing a brick at a co-worker out of frustration, see p. 264). These expectations to take risks are prevalent in contemporary jobsite culture and jobrelated injuries could be attributed to them (lacuone, 2005). As well, lacuone (2005) states that most men are aware of the hierarchy and that certain attitudes and beliefs can affect their acceptance on the jobsite. According to Breslin, Polzer, MacEachen, Morrongiello, and Shannon (2007), younger workers also tend to have higher rates of occupational injuries, potentially as a result of their lower status on job sites, particularly in male-dominated settings. Younger workers' understandings of legitimate safety risks were shaped around gender dimensions in a way that maintains hierarchical power relations.

Both men and women ascribe to masculine ideals, and researchers have found that, when women ascribe to masculine ideals (even temporarily while at work), they take more safety risks than men (Breslin et al., 2007). Younger men are more likely to suppress their complaints about unsafe working conditions in an attempt to appear more mature and experienced to their superiors (Breslin et al., 2007). The suppression of complaints was also found among women working in male-dominated fields. A female participant reported that both she and her male co-workers would frequently lift heavy items by themselves because they did not want their boss to think they were too weak to perform their jobs (Breslin et al., 2007). Much like women in male-dominated trades, young male workers may perceive the need to prove their competency through displays of masculinity, which include learning how to master risk and danger at work. Breslin and colleagues (2007) suggest that younger workers of any gender are socialized to accept certain risks as part of the job and to stifle their concerns about working conditions in an attempt to minimize challenges to authority.

Adherence to male role norms has also been examined in relation to male help-seeking behaviour in terms of psychological and physical health. Within western cultures, help-seeking behaviour in men can be understood as "a function of the way both the socialization and the social construction of masculinity transacts with the social psychology of giving and receiving help" (Addis \& Mahalik, 2003 , p. 12). When internalizing gender roles, men are more likely to experience negative health impacts, such as additions and chronic medical conditions, and are less likely to seek professional help than women (Addis \& Mahalik, 2003; Courtenay, 2000). Attempting to adhere to an idealized stereotypical form of masculinity -- one that does not coincide with an individual's personal level of masculinity -- results in an internal conflict situation that has been associated with a decrease in help-seeking behaviour (Vogel, Heimerdinger-Edwards, Hammer, and Hubbard, 2011). Vogel et al. (2011) determined that the majority of males reported seeking help less frequently than females and extended the literature pertaining to male help-seeking attitudes to a population of ethnically diverse, non-university males with varying sexualities. As a stereotypically male-dominated field, the trades offer a unique environment to explore adherence to male role norms in relation to help-seeking behaviours, and the overrepresentation of men in the trades. However, it cannot be assumed that all males that work within the trades possess similar degrees of traditional masculinity, or fit within the stereotypical ideals of a North American man. Therefore, when examining help-seeking behaviour in relation to workplace safety decisions, individual levels of masculinity in relation to adherence to gender norms should be explored. By presenting male participants with a safety-related vignette followed by a brief survey, we investigated how masculine attitudes in male-dominated fields impact men in relation to workplace safety decisionmaking.

For this study, we generated several hypotheses. Research studying gender-segregation in the trades has associated females' negative experiences and safety risks with masculine attitudes present in the workplace (Breslin et al., 2007; Denissen \& Saguy, 2014; Maclsaac \& Domeme, 2013; Ness, 2012). Therefore, it is hypothesized that participants with higher scores on scales measuring adherence to male role norms will be less likely to ask either gender of hypothetical co-worker for assistance with a heavy item (Hypothesis 1). However, if the participant were to ask for help, he would be more likely to ask for help from a male co-worker (Hypothesis 1a). Supported by Breslin and colleagues' (2007) findings that younger workers will risk injury to prove their competency to more experienced workers, it is also hypothesized that younger men will be 
less likely to seek help than older men (Hypothesis 1 b). Although younger males may be more receptive to working with women in the trades, they may be unlikely to ask a woman to help them out of fear that their more experienced co-workers will view them as weak and incapable. As well, previous research has identified that female trades workers often are viewed as less capable and competent than their male counterparts, as evidenced by fewer job opportunities, promotions, and apprenticed hours offered to females (Maclsaac \& Domeme, 2013). Due to these findings, it is predicted that higher scores on scales measuring adherence to male role norms will be associated with the perception of female co-workers as less capable and less competent than their male coworkers (Hypothesis 2).

\section{Methods}

\section{Ethics}

The current study was approved on ethical grounds by the University of Saskatchewan Department of Psychology Research Ethics Committee.

\section{Participants}

Participants were drawn from the general public using social media. A statement identified that we were psychology undergraduate students conducting a research study on how general attitudes about men and women relate to real world decision-making in the workplace (focusing on construction, mining, and oil and gas) (See Appendix B). This statement was posted on the researchers' personal Facebook pages, as well as other public Facebook pages (such as local radio stations). A total of 59 respondents completed the survey and demographic information was used to filter these results to our target demographic. Non-trades (15) and non-male (7) participants were excluded, resulting in 37 overall usable responses. Participants ranged in age from 18 to 53 with a mean age of $29.62(S D=10.46)$. The majority of the participants were Caucasian (91.9\%), identified as heterosexual (97.3\%), and identified as politically conservative $(59.5 \%$ versus $35.1 \%$ as liberal). Participants were informed that their data would remain confidential and no identifying information would link participants' identities to their responses.

\section{Materials and Stimuli}

Workplace situation vignettes. Participants were asked to read a vignette describing a workplace situation in which they faced a potential safety hazard and had the option of asking a co-worker for assistance (see Appendix A). In order to make the vignette applicable to a wide range of fields, the researchers chose to keep the description of the task relatively general: loading heavy materials onto a truck to move to a new job site. The task of lifting heavy objects was chosen because it has been shown to be the cause of many common workplace injuries. Work Safe Alberta (2012) identified that $46.9 \%$ of injuries within the trades were due to sprains, strains, and tears, with the back being the most common body part injured. WorkSafeBC (2012) identified back strain as a widespread and common workplace injury that impacts one fifth of people in British Columbia in both trade and non-trade fields. Back injuries were found to occur most frequently in occupations that require considerable physical exertion, such as construction and healthcare (WorkSafeBC, 2012).

Consultations with various lay experts verified that a lifting task is relevant to a wide range of fields within the trades (V. Singh, personal communication, January 24, 2015; K. Isbister, personal communication, January 13, 2015). As well, a lay expert within the trades identified the importance of stating that the co-worker was not busy and had the same level of training as the participant (G. Bartholomew, personal communication, January 27, 2015). For authenticity, it was also suggested that the vignette mention that workers other than John or Jennifer were present, but not immediately available to help (K. Isbister, January 30, 2015). Additionally, a time pressure (e.g., statement regarding completion time for the task or additional tasks) was excluded because it was determined that a time pressure may introduce a confounding variable in which participants may choose to ask for help based on the time available or priority of tasks, instead of the gender of person available to help.

The vignette describes a workplace scenario in which the participant must decide to lift a heavy item on his own or ask for help from a co-worker of either sex. The vignettes presented to the participants were identical, except for the name of the co-worker available to help. This ensured that any differences in perceived competency, capability, and helpfulness ratings could be attributed to the gender of the co-worker available to help. The names John and Jennifer were used as research indicated that these names are the most gender recognizable and equivalent in likeability (Moss-Racusin, Dovido, Brescoll, Graham, \& Handelsman, 2012).

\section{Measures}

Participants completed scales rating the perceived workplace ability of men and women in general, focusing on competence, capability, and helpfulness. Following this, participants completed the Male Role Norms Inventory (MRNI-SF), Neosexism Scale (NSS), Work Safety Scales (WSS), and demographics.

Manipulation check questions. To ensure participants correctly comprehended the vignette, participants were asked to complete two manipulation check questions. The first question asked the name of the co-worker and 
provided four options - Sam, Peter, John/Jennifer, or Rachel. The second question asked the weight of the item and provided two options - heavy or light.

Participants' comfort level asking for help. Participant comfort level was measured by asking the participant to rate the statement "How comfortable are you asking for help on a jobsite?" using a sliding scale of o to 100, which increased in increments of 10. For example, starting at the far left, $\mathrm{O}=$ low end of the spectrum (i.e., extremely uncomfortable) and at the far right, $100=$ high end of the spectrum (i.e., extremely comfortable).

Perceived workplace ability of John and Jennifer. Depending on the condition each participant completed, participants were asked to rate a hypothetical co-worker (either John or Jennifer) on his or her perceived workplace competence, perceived physical capability, and perceived helpfulness. These perceptions were rated using a sliding scale of o to 100, which increased in increments of 10 . For example, starting at the far left, $\mathrm{o}=$ low end of the spectrum (i.e., extremely incompetent) and at the far right, $100=$ high end of the spectrum (i.e., extremely competent) for competency, physical capability, and helpfulness. The perceived ability of John or Jennifer was measured separately from the perceived workplace ability of coworkers in general.

Perceived Workplace Ability Scale (Men and Women) (PWAS-M/W). To measure perceived workplace ability, the researchers created a short scale. This scale evaluated perceived workplace ability using a sliding scale of o to 100, increasing in increments of 10 . For example, starting at the far left, $\mathrm{O}=$ low end of the spectrum (i.e., extremely incompetent) and at the far right, $100=$ high end of the spectrum (i.e., extremely competent) for competency, physical capability, and helpfulness. The scale consisted of three items each for men and women: (a) "in general, how competent do you think women/men are on a jobsite?"; (b) "in general, how physically capable do you think women/men are on a jobsite?"; and (c) "in general, how helpful do you think women/men are on a jobsite?" Items were summed to form a perceived workplace ability scale, with higher scores indicating greater perceived ability.

Male Role Norms Inventory - Short (MRNI-SF). A short version of the Male Role Norms Inventory (Levant, Hall, \& Rankin, 2013) was used to measure personal endorsement of traditional masculine ideologies. Twentyone items on a five-point Likert scale ( 1 = strongly disagree and $5=$ strongly agree) assessed participants' agreement with male role norms and behaviours. Subscales for this measure include restrictive emotionality, self-reliance through mechanical skills, negativity toward sexual minorities, avoidance of femininity, and importance of sex, dominance, and toughness. Example items include "homosexuals should never marry," "men should always be the boss," and "men should watch football games instead of soap operas." The wording of some of the items was altered to be pertinent for Canadians and for clarification purposes. For example, "homosexuals" was changed to "gay men;" "homosexual bars" was changed to "gay bars;" and "President" was changed to "Prime Minister." Additionally, qualifying words such as "always" and "never" were removed from items in which the qualifying word competed with the Likert scale. These qualifying words were removed to improve clarity and reduce ambiguity; for example, "a man should always be the boss" was changed to "a man should be the boss." Items were totalled to form a single measure of masculinity for each participant, with higher scores indicating greater adherence to traditional masculine ideology. This scale was chosen because it was found to have relatively high internal reliability: $\alpha=.92$ for men and $\alpha$ $=.94$ for women (Levant et al., 2013).

Neosexism Scale (NSS). The Neosexism Scale (Tougas et al., 1995) was used to assess modern sexist beliefs about women in the workplace. This particular scale was chosen because previous research has found that many of the problems faced by career women originate from neosexism (Glick, Lasen, Johnson, \& Branstiter, 2005). The scale consists of 11 items scored on a five-point Likert scale ( 1 = strongly disagree and $5=$ strongly agree). Items on this scale assess participants' tendency to $(a)$ deny that discrimination against women exists, (b) antipathize complaints about discrimination, and (c) reinforce a paternalistic view of women. Sample NSS items include, "it is difficult to work for a female boss" and "women's requests in terms of equality between the sexes are simply over-exaggerated." The wording of the items was altered to be pertinent for Canadians; "America" was changed to "Canada." Some items were reverse-coded and items were totalled to form a single measure of neosexism, with higher scores indicating greater endorsement of neosexist beliefs. Campbell, Schellenberg, and Senn (1997) determined that the Neosexism Scale directly assessed workplace sexism (in addition to modern sexism) and had a relatively high internal reliability $(\alpha=.81)$ that was superior to the Modern Sexism Scale $(\alpha=.65)$.

Work Safety Scale (WSS). The Work Safety Scale (Hayes, Perander, Smecko, \& Trask 1998) was used to measure participants' perceptions of workplace safety. Thirty items scored on a five-point Likert scale ( $1=$ strongly disagree and $5=$ strongly agree) were used to evaluate perceptions regarding safety on the jobsite. Items were selected from a total of three out of five subscales: individual perceptions of participants' (a) own safety, (b) coworker safety, and (c) workplace safety program. Sample WSS items for the perceived safety of one's own job include "safe, dangerous, or scary." The second subscale measured participants' assessment of their co-workers' safety practices. Sample items for co-worker safety include 
"encourage others to be safe" and "look out for other's safety." The third subscale measured participants' assessment of their workplace safety program. Sample items for workplace safety program include determining whether the safety program is "worthwhile" or "useful." Negatively worded items were reverse-coded and items in each subscale were totalled to form subscale measures; all items were totalled to form an overall work safety scale. For the subscales and the overall work safety scale, higher scores indicate greater perceptions of safety. Hayes et al. (1998) found the subscales to possess adequate subscale score reliability (Cronbach's alpha > .87).

Demographic information. Participants completed a demographic questionnaire that included age, gender, ethnicity, political orientation, sexual orientation, field of employment, job title, and location. Options were provided for participants to select responses, with space provided for additional responses. Demographics were used to ensure participants were typically employed in the trades (construction, mining, and oil and gas) and were male, and to break down overall survey response data into meaningful groups (e.g., age ranges).

\section{Procedure}

The survey was created and distributed using FluidSurveys, a Canadian online software tool for survey creation and distribution. To ensure the vignettes reflected the desired workplace situation and the survey questions were clear and coherent, several lay experts completed a pilot test of the survey. Participants were invited to complete the survey via a direct link on the researchers' personal Facebook accounts. At the beginning of the survey, participants were directed to the consent form. After giving informed consent, the participants were asked to choose a number between 1 and 10, where 1-5 directed them to the female condition (Jennifer) and 6-10 directed them to the male condition (John). Participants were then directed to a short vignette in which either a female (Jennifer) or male (John) co-worker was available to assist with lifting a heavy object. Following the vignette, two manipulation check questions were administered to ensure participants attended to the key objectives in the scenario. In the next sections, the participants completed the individual questions pertaining to the dependent variable (for example: "how would you respond in this situation?"), perceived workplace ability of the hypothetical co-worker (John or Jennifer), participant comfort level with seeking help on a job-site, the PWAS-M/W, MRNI-SF, NSS, and the WSS. Upon completing the scale items, participants filled out demographic information. The scale items and demographic questions were identical for each participant. After completion or withdrawal, participants were directed to a debriefing form that provided more information about the purpose of this study.

\section{Design}

Overall, this experiment was a single factor (co-worker gender: male, female) between-subjects design. The independent variable of co-worker's gender occurred at two levels: male and female. The key dependent variables were participants' choice to ask the hypothetical co-worker for help or not; their responses to safety questions regarding perceptions of competency, capability, and helpfulness of the co-worker; and the participants' scores on the PWAS$M / W$. Additional dependant variable measures were based on scores on the NSS (Tougas et al., 1995), MRNI-SF (Levant et al., 2013), and the WSS (Hayes et al., 1998).

\section{Data Analysis}

Descriptives and scale score reliability were calculated for each scale. Data were analysed using frequency analysis, paired samples t-tests, independent samples t-tests, and Pearson's correlations. To determine help-seeking behaviour in a workplace safety situation, the participants' responses to the situation presented in the vignette (asking John/Jennifer, someone else, or lifting the item on their own) were analyzed based on frequency, as the question resulted in nominal data. Relationships between the scales and comfort level asking for help, age, ethnicity, sexuality, and political affiliation were calculated using Pearson's $r$ correlations. Independent samples t-tests were run to determine if the evaluative target's gender influenced the perceived competence, physical capability, and helpfulness of the co-worker (John or Jennifer) available to assist with lifting the item. To determine relationships between the scales, correlations were run comparing the summed scores on the MRNI-SF, NSS, WSS (including subscales of job safety, co-worker safety, and safety program), and PWAS$\mathrm{M} / \mathrm{W}$ on the total sample and on the sample divided into the Jennifer and John conditions.

\section{Results}

Scale descriptives and scale score reliabilities can be found in Table 1. Overall, the sample was slightly below the midpoint for scores on the MRNI-SF (Midpoint $=63, M=$ 60.5), demonstrating less endorsement of male role norms. As evidenced on the NSS, the sample possessed somewhat positive attitudes towards women in that the mean total scale score was slightly below the midpoint (Midpoint $=33$, $M=27.84$ ). Positive attitudes toward workplace safety were displayed because on the whole, the sample was over the midpoint (Midpoint $=90, M=106.2$ ) for the WSS scale. 
Additionally, the scores indicate that participants showed a positive perception of both male and female co-worker abilities because the sample was over the midpoint. All scales demonstrated good scale score reliability (Cronbach's alphas ranged from .85 to .94). A significant difference in perceptions of men's $(M=193.24, S D=67)$ and women's abilities $(M=176.49, S D=70.33)$ did not emerge, $t(36)=1.73, p=.09, d=.24$. As anticipated, scores on the MRNI-SF correlated with the NSS, $r(35)=.69, p<.001$, and the WSS correlated with WSS-JS, $r(35)=.72, p<.001$, WSSCWS, $r(35)=.69, p<.001$, and WSS-SP subscales, $r(35)=$ $.80, p<.001$.

Table 1: Descriptive Statistics and Alpha Coefficients.

\begin{tabular}{lcccccc}
\hline Measure & $M$ & SD & $\alpha$ & $95 \% \mathrm{Cl}$ & $\begin{array}{c}\text { Possible } \\
\text { Range }\end{array}$ & Actual Range \\
\hline MRN-S & 60.35 & 12.30 & .89 & $.83-.94$ & $21-105$ & $41-98$ \\
NSS & 27.84 & 6.65 & .85 & $.77-.91$ & $11-55$ & $17-49$ \\
WSS & 103.62 & 15.55 & .91 & $.86-.94$ & $30-150$ & $69-135$ \\
WSS-JS & 39.09 & 7.57 & .87 & $.80-.92$ & $10-50$ & $17-46$ \\
WSS-CWS & 35.62 & 6.35 & .86 & $.79-.92$ & $10-50$ & $22-50$ \\
WSS-SP & 36.92 & 7.22 & .91 & $.86-.95$ & $10-50$ & $21-50$ \\
PWAS-M & 193.24 & 67.00 & .91 & $.84-.95$ & $0-300$ & $0-300$ \\
PWAS-W & 176.49 & 70.33 & .94 & $.90-.97$ & $0-300$ & $0-300$ \\
\hline
\end{tabular}

Note $\mathrm{CI}=$ confidence interval; MRN-S = Male Role Norms Inventory Short; NSS = Neosexism Scale; WSS= Work Safety Scale; WSS-JS = Work Safety Scale - Job Safety; WSS-CWS = Work Safety Scale - Co-worker Safety; WSS-SP = Work Safety Scale - Safety Program; PWAS-M = Perceived Workplace Ability Scale - Men; PWAS-W = Perceived Workplace Ability Scale - Women.

Hypothesis 1 and 1 a. It was hypothesized that participants with higher scores on the MRNI-SF would be more likely to lift the equipment in the safety situation by themselves than ask a member of either of the two genders. However, if the participant was inclined to ask for assistance, he would ask the male (i.e., John) more frequently than the female (i.e., Jennifer). Results did not support these hypotheses, as $86.5 \%$ of participants chose to ask the co-worker available in the vignette for help, regardless of gender. Comfort level asking for help on a jobsite did not correlate with the MRNI-SF, $r(35)=.15, p=$ .37 , NSS, $r(35)=.17, p=.32$, or WSS, $r(35)=.03, p=.86$.

Hypothesis $1 \mathrm{~b}$. It was hypothesized that age would correlate significantly with help-seeking behaviour. To analyze this hypothesis, a correlation coefficient was calculated. This hypothesis was not supported, $r(35)=.25, p$ $=.14$, in that younger participants were not less likely to seek help. Additionally, no significant gender differences emerged on evaluations of perceived competence of John $(M=62, S D=26.67)$ and Jennifer $(M=70.59 ; S D=27.03)$, $t(35)=.97, p=.34$; perceived physical capability of John $(M=$ $66.5, S D=27.58)$ and Jennifer $(M=57.65, S D=27.5), t(35)=$ $.97, P=.34$; or perceived helpfulness of John $(M=60 ; S D=$ $27.33)$ and Jennifer $(M=65.88, S D=33.55), t(35)=.59, p=$ .56 , in relation to assisting the participant with lifting the item in the imagined scenario.
Hypothesis 2. The second hypothesis stipulates that greater adherence to male role norms will be more strongly correlated with greater perceived incompetence of one's female co-workers than one's male co-workers (as measured with the PWAS-M and -W). As outlined in Table 2 , overall, scores on the PWAS-W were significantly negatively correlated with scores on the MRNI-SF, such that higher scores on the MRNI-SF were associated with female co-workers being perceived as generally less competent on a jobsite, as measured by the PWAS-W. However, a similar relationship did not emerge between scores on the MRNISF and the evaluations of male participants' perceptions of their male co-workers (as measured by the PWAS-M). The sample as a whole showed no significant association between perceptions of workplace safety (as measured with the WSS) and adherence to male role norms or neosexist beliefs. 
Table 2: Intercorrelations Among Key Variables: Total Sample.

\begin{tabular}{lccccccc}
\hline Variable & 1 & 2 & 3 & 4 & 5 & 6 & 7 \\
\hline 1. MRNI-SF & - & & & & & & \\
2. NSS & $.69 * * *$ & - & & & & & \\
3. WSS & -.13 & -.08 & - & & & & \\
4. WSS-JS & -.09 & -.21 & $.72 * * *$ & - & & & \\
5. WSS-CWS & -.21 & -.06 & $.69^{* * *}$ & .38 & - & & \\
6. WSS-SP & .01 & .10 & $.80^{* * *}$ & .39 & $.53^{*}$ & - & \\
7. PWAS-M & .11 & .14 & $.33^{*}$ & .23 & .09 & .40 & - \\
8. PWAS-W & $-.48^{* *}$ & $-.44^{* *}$ & .14 & .29 & .40 & .15 & $.63^{* * *}$ \\
\hline
\end{tabular}

${ }^{*}=$ Correlation is significant at 0.05 (2-tailed).

${ }^{* *}=$ Correlation is significant at 0.01 (2-tailed).

${ }^{* * *}=$ Correlation is significant at 0.001 (2-tailed).

Note. MRNI-SF = Male Role Norms Inventory Short; NSS = Neosexism Scale; WSS= Work Safety Scale; WSS= Work Safety Scale; WSS-JS = Work Safety Scale - Job Safety; WSS-CWS = Work Safety Scale - Co-worker Safety; WSS-SP $=$ Work Safety Scale - Safety Program; PWAS-M = Perceived Workplace Ability Scale - Men; PWAS-W = Perceived Workplace Ability Scale - Women.

Further, when reviewing the correlation between MRNI-SF and PWAS-W, it appeared that the magnitude of the correlation between scores on the PWAS-W and MRNI-SF in the female (Jennifer) condition differed significantly from the magnitude of the correlation between scores on the PWAS-W and MRNI-SF in the male (John) condition. To confirm the significance of this difference a Fisher's r-to-z transformation was conducted, which indicated that the correlation coefficients differed significantly from one another, $z=-1.65, p<.05$. For participants in the female condition, PWAS-W ratings were more strongly negatively correlated with MRNI-SF than the correlation seen with the total sample or in the male condition. A similar analysis was conducted to examine whether a significant difference in the magnitude of the correlations emerged between scores on the WSS-CWS and the MRNI-SF for the female condition in comparison to the male condition (see Tables 3 and 4). Results indicated that the correlation coefficients significantly differed in magnitude from one another, $z=$ $2.16, p=.015$. For participants in the male condition, WSSCWS ratings are more strongly negatively correlated with MRNI-SF than the correlation seen with the total sample or in the female condition. This same pattern was observed with the NSS, such that WSS-CWS more strongly negatively correlated with NSS for participants in the male condition. Table 4 illustrates that for participants in the male (John) condition, neither PWAS-M nor PWAS-W correlated with MRNI-SF or NSS.

Table 3: Intercorrelations Among Key Variables: Female (Jennifer) Condition

\begin{tabular}{|c|c|c|c|c|c|c|c|}
\hline Variable & 1 & 2 & 3 & 4 & 5 & 6 & 7 \\
\hline 1. MRNI-SF & - & & & & & & \\
\hline 2. NSS & $.76 * * *$ & - & & & & & \\
\hline 3. WSS & .21 & .36 & - & & & & \\
\hline 4.WSS-JS & .01 & -.08 & $.72 * *$ & - & & & \\
\hline 5.WSS-CWS & .13 & .46 & $.52 *$ & -.04 & - & & \\
\hline 6. WSS-SP & .32 & .43 & $.76 * * *$ & .33 & .23 & - & \\
\hline 7. PWAS-M & .10 & .20 & .40 & -.10 & .28 & $.71 * *$ & - \\
\hline 8. PWAS-W & $-.62 * *$ & .45 & -.01 & -.12 & -.09 & .22 & $.63 * *$ \\
\hline
\end{tabular}

${ }^{*}=$ Correlation is significant at 0.05 (2-tailed).

${ }^{* *}=$ Correlation is significant at 0.01 (2-tailed).

$* * * *$ Correlation is significant at 0.001 (2-tailed).

Note. MRNI-SF = Male Role Norms Inventory Short; NSS = Neosexism Scale; WSS= Work Safety Scale; WSS= Work Safety Scale; WSS-JS = Work Safety Scale - Job Safety; WSS-CWS = Work Safety Scale - Co-worker Safety; WSS-SP = Work Safety Scale - Safety Program; PWAS-M = Perceived Workplace Ability Scale - Men; PWAS-W = Perceived Workplace Ability Scale - Women. 
Table 4: Intercorrelations Among Key Variables: Male (John) Condition.

\begin{tabular}{|c|c|c|c|c|c|c|c|}
\hline Variable & 1 & 2 & 3 & 4 & 5 & 6 & 7 \\
\hline 1. MRNI-SF & - & & & & & & \\
\hline 2. NSS & $.55^{*}$ & - & & & & & \\
\hline 3. WSS & $-.46 *$ & $-.48 *$ & - & & & & \\
\hline 4.WSS-JS & -.26 & -.42 & $.75^{* *}$ & - & & & \\
\hline 5. WSS-CWS & $-.57^{* *}$ & $-.58 * *$ & $.79 * *$ & .38 & - & & \\
\hline 6. WSS-SP & -.27 & -.17 & $.82 * *$ & .39 & .53 & - & \\
\hline 7. PWAS-M & .18 & .06 & .31 & -.10 & .28 & $.71 * *$ & - \\
\hline 8. PWAS-W & -.13 & -.41 & .34 & -.12 & .09 & .22 & $.63^{* *}$ \\
\hline
\end{tabular}

$*$ Correlation is significant at 0.05 (2-tailed).

$* *$ Correlation is significant at 0.01 (2-tailed).

${ }^{* * *}=$ Correlation is significant at 0.001 (2-tailed).

Note. MRNI-SF = Male Role Norms Inventory Short; NSS = Neosexism Scale; WSS= Work Safety Scale; WSS= Work Safety Scale; WSS-JS = Work Safety Scale - Job Safety; WSS-CWS = Work Safety Scale - Co-worker Safety; WSS-SP = Work Safety Scale - Safety Program; PWAS-M = Perceived Workplace Ability Scale - Men; PWAS-W = Perceived Workplace Ability Scale - Women.

\section{Discussion}

This study investigated the impact of adherence to male role norms and neosexist beliefs in relation to male decision-making concerning help-seeking behaviour, workplace safety, and perceptions of co-worker competence. Hypothesis 1 was designed to examine the participants' help-seeking behaviour in a safety situation in relation to adherence to male role norms and gender of the co-worker available to help (hypothesis 1a). This hypothesis was not supported, as $86.5 \%$ of participants chose the coworker available in the vignette to help, regardless of participants' MRNI-SF scores or gender of the co-worker available to help. These results may be due to a lack of ambiguity within the vignette and the small number of participants in the study.

Age was hypothesized to positively correlate with help-seeking behaviour (hypothesis $1 \mathrm{~b}$ ); however, results indicated that participants' personal comfort level asking for help on a jobsite did not correlate with participant age or with scores on MRNI-SF, NSS, WSS, and PWAS-M/W. These results may be due to differences between the current study and previous studies in age of participants and workplace experience. Additionally, it is possible that the sample size was too small to detect an effect. -workers and may impact safety decision-making for all workers in male-dominated fields.

Hypothesis 2 was designed to examine the relationship between tradesmen's adherence to male role norms and perceived workplace ability of female co-workers. This hypothesis was supported: Participants with greater adherence to male role norms rated female co-workers as less competent, less physically capable, and less helpful on the jobsite as compared to male co-workers. Additionally, participants' perception of their male and female coworker's jobsite abilities and co-worker safety differed between the male (John) and female (Jennifer) conditions. Tradesmen's adherence to male role norms may influence their attitudes toward both male and female co-workers and may impact safety decision-making for all workers in male-dominated fields.

It is plausible that the primary hypothesis regarding participants' choice of person to assist with the task in the vignette was not supported due to potential issues with the vignette. The wording of the vignette may have acted as an anchor that guided participants' decisions on how to respond to the situation (Pfiefer \& Ogloff, 2003). Due to the manner in which the situation was framed in the vignette, and the purported qualifications of the co-worker available to help, the obvious choice for participants was the coworker described in the vignette, regardless of gender. Participants were left with virtually no options that would not immediately identify them as sexist or unsafe and, in effect, were only given the choice of risking their safety, appearing obviously sexist, or choosing the co-worker the vignette identified as available to help. This was exemplified by a written response from one of the participants who stated, "the item is to [sic] heavy to lift alone. John is nearby, not busy and has similar training."

The above statement regarding the structure of the vignette is similar to findings in Pfiefer and Ogloff's (2003) investigation of racial discrimination using a mock jury. They determined that participants' reliance on personal stereotypes depended on the amount of information they were given about the "defendant." When there was less information provided, or more ambiguous information provided, the participants relied more heavily on personal 
stereotypes to aid in their decision. However, when participants were given standardized directions that removed ambiguity, they followed these directions even when they contradicted their personal beliefs. Monin and Miller (2001) emphasized the importance of ambiguity when using vignettes, determining that situational ambiguity, in which the behaviour can be attributed to an external reason, enables a person to act in accordance with their personally held stereotypes and biases. Within the current study, a lack of situational ambiguity did not provide participants with an external reason to attribute their choice to, potentially accounting for the lack of support for the primary hypothesis.

Lack of support for hypothesis $1 \mathrm{~B}$ may due to differences in participant age and workplace experience between the current study and previous studies. Breslin et al. (2007) examined workplace safety in relation to age, focusing on four age ranges, the youngest of which was teenagers aged 15-19. They determined that younger workers were more likely to take safety risks on the job. Within the current study, all participants were above the age of 18 , with a median age of 25 , and many participants reported employment in the trades for over a year. Breslin et al. (2007) investigated young people new to the workforce. This difference in participant ages and workplace experience between the current study and the Breslin et al. (2007) study could explain the lack of associations between age and workplace safety behaviours or comfort levels asking for help in the current study.

The second hypothesis, that participants' adherence to male role norms would negatively correlate with perceptions of female co-worker workplace ability, was supported. For the sample as a whole, participant scores on MRNI-SF were significantly negatively correlated with scores on PWAS-W, such that participants with greater adherence to male role norms rated female co-workers as less competent on a jobsite. This correlation was analyzed according to target gender and found that in the Jennifer condition, there was a significantly stronger negative correlation between perceived female ability and adherence to male role norms, yet in the John condition there was no significant correlation between perceived female ability and adherence to male role norms. For the total sample (and both male and female conditions), perceptions of male coworker ability did not correlate with participants' adherence to male role norms. The contradiction of choosing Jennifer to help lift the heavy item, yet rating actual female coworkers as lower in ability than male co-workers, seems to support the possibility that participants chose the person in the vignette to help regardless of the participant's personal perceptions.

While the vignette did not seem to have significantly impacted participants' choice of person to help with the task, it did appear to have primed participants to think about their own personal experiences with female coworkers or traditional gender stereotypes. The association of perceived female co-worker ability with tradesmen's adherence to male role norms appears to support the qualitative (interview and focus group) findings of previous literature (i.e., Denissen \& Saguy, 2014; Maclsaac \& Domeme, 2013; Ness, 2012). Tradesmen with greater adherence to male role norms who read the vignette, in which a female was available to help, rated female coworkers as less competent than male co-workers. In a similar manner, working alongside a tradeswomen may prime traditional gender stereotypes for tradesmen, resulting in the negative experiences tradeswomen reported in previous literature (Denissen \& Saguy, 2014; Maclsaac \& Domeme, 2013; Ness, 2012).

Maclsaac and Domeme (2013) and Ness (2012) also attributed tradeswomen's tendencies to over work and take safety risks to adherence to traditional masculine attitudes. Results of the current study revealed a negative correlation between participants' WSS scores and MRNI-SF and NSS. This association was only present for participants in the John condition. Further analysis revealed that this correlation was present for perceptions of co-worker safety, indicating that participants viewed their jobs and workplace safety programs as positive, yet perceived their co-workers to behave in an unsafe manner. When asked to consider their actual co-workers, participants in the John condition with higher scores on the MRNI-SF and NSS rated their coworkers as lower in perceived workplace safety behaviour.

Participants in the John condition may have rated their co-workers as less safe because the vignette could have primed participants to envision the stereotypical tradesman. Conversely, they may have completed the assessment based on the fictional co-worker presented in the vignette instead of their personal experiences with actual co-workers. A third possibility is that pluralistic ignorance may have contributed to participants' rating their co-workers as lower in safety practices. According to Miller and McFarland (1991), pluralistic ignorance occurs when an individual believes that their own attitudes and judgements differ greatly from those around them. Group members' attitudes and judgements are often perceived as much more extreme than the individual's own attitudes and judgements. This occurs within peer groups, which results in widespread exaggeration of the group's perceived private views (Miller \& McFarland, 1991). Pluralistic ignorance can cause individuals to accept and conform to the misguided assessments of group norms (Prentice \& Miller, 1993). Based on participants' personal perceptions of co-workers' safety, it is evident that participants do not recognize safety as a priority among their co-workers, and consequently risktaking behaviour is recognized as part of the social norm on the jobsite. Therefore, participants will be more likely to 
take risks regardless of whether or not they personally value workplace safety.

A major limitation of the current study is the possibility that the small sample size (37 participants) introduced Type II errors. A Type II error is the possibility that the independent variable did have an effect, but that no difference between the groups was detected (Ray, 2011). The vignette may have had a small effect on participants choice of co-worker; however, a sample of 37 likely was not large enough to detect either a small or medium effect size. Similarly, there may have been a relationship between a participant's age and help-seeking behaviour that was not detected. The majority of the literature examining gender segregation in the trades appears to be qualitative research which does not lend itself to estimates of effect sizes. However, Vogel et al.'s (2011) study, which examined male helping-seeking behaviour in relation to notions of masculinity in the context of seeking psychological help, suggests that effect sizes are likely to be small.

Another limitation is the possibility that social desirability bias contributed to participants' relatively lower ratings of co-worker safety. Participants may have rated their own safety and their work safety program as being relatively higher in order to appear more favourable to the researchers. Conversely, participants may not have been concerned whether their co-workers appear favourable, and therefore may have been more inclined to answer the items on this subscale more honestly. Another indication that social desirability may have influenced the study is found in a comparison of mean scale scores to scale midpoints. Considering previous research (Denissen \& Saguy, 2014i Maclsaac \& Domeme, 2013), overall scale scores for tradesmen were anticipated to be above the midpoint on the MRNI-SF (Midpoint $=63$ ) and NSS (MP = 33) measures. However, results demonstrated that mean scale scores were below the midpoint on both MRNI-SF $(M=60.5)$ and NSS $(M=27.84)$ measures. Due to the high rate of injury in the trades (Government of Canada, 2011), mean scores below midpoint on WSS (Midpoint $=90$ ) were expected for work safety. However, the participants' overall rating of work safety $(M=106.2)$ indicates that they perceive their workplaces to be generally safe. This incongruity between researchers' expectations and participants' recorded scores suggest that participants may have responded in a socially desirable manner.

Additionally, it is possible that due to recruitment methods, the sample of participants is not representative of Canadian tradesmen as a whole and may have been fairly homogenous. The main recruitment method was social media (i.e., Facebook) and as a result, the survey may have reached participants that were similar to the researchers, as well as the other participants. Since the researchers are university-educated, Caucasian, middle-class, and approximately mid-twenties, it seems likely that social media connections would also largely fit into these categorizations. Demographic information supports this, as the majority (98\%) of participants self-identified as Caucasian with a median age of 25 . Additionally, the majority of participants' text responses were written in full, coherent sentences with few grammatical mistakes. This indicates relatively high writing ability, suggesting that participants are comparably educated. A sample that potentially represents only a portion of a population may somewhat compromise the generalizability of a study, and thus the results of the present study may not be applicable to the trades as a whole.

\section{Conclusions and Future Study}

Overall, the current study has demonstrated that masculine attitudes are present in some male-dominated fields, such as the trades, and may have a negative impact on job safety. Based on participants' overall scores on the PWASW, female co-workers were viewed as less competent, less physically capable, and less helpful on the jobsite. Harbouring these negative attitudes did not directly impact work safety decisions in this study, as participants chose to ask the co-worker identified as available to help regardless of the co-worker's perceived gender. However, selection of co-worker to assist with the task may have been compromised by a lack of ambiguity within the vignette and the sample size may have been too small to detect an effect.

Future research in this area might benefit from incorporating multiple vignettes that possess varying degrees of ambiguity into a study with a larger sample size. Situational ambiguity can be defined as the extent to which the action or decision can be attributed to an external reason (Monin \& Miller, 2001; Pfiefer \& Ogloff, 2003). For example, in a slightly ambiguous situation, it would be possible for participants to attribute behaviour to an external reason. The vignette in the current study was nonambiguous; there was no possibility for participants to attribute their selection to an external reason. Controlling and measuring the amount of ambiguity would ensure that ambiguity (or lack thereof) is not limiting the participant's ability to respond to the workplace situation based on their personal stereotypes. Specifically, additional vignettes might include one that is non-ambiguous, one that is slightly ambiguous, and one that is highly ambiguous.

The present study used a physical task of lifting a heavy item, due to its association with common workplace injury. However, not all the tasks associated with maledominated fields are physical and it is likely that perceptions of target and co-worker ability change with the type of task. A limitation of the current study was not differentiating between a physical task and mental task. Therefore, future research would benefit from the 
incorporation of a mental task. Thus, researchers could then determine whether differences exist between evaluations of targets and co-workers when the task presented in the vignette is physical in comparison to mental.

Future research may also consider examining body types to determine what role physical appearance has in male help-seeking behaviour on the jobsite. Adherence to male role norms may be influenced by physical body size. Masculinity is associated with body size, yet gender roles are socially constructed, suggesting that men who are not stereotypically masculine in a physical sense may still internalize traditional gender roles and experience a greater level of internal conflict. Vogel et al. (2011) associated the dissonance felt when internalized ideals of masculinity do not match actual levels of masculinity with decreases in help-seeking behaviour. Responses in the current study suggest that men who do not adhere to typical masculinity in a physical sense may "self-select" non-trades employment. Thus, future researchers may obtain different results if varying body sizes were included in the vignette conditions.

Overall, studies investigating the relationship between men's adherence to male role norms and workplace safety decision-making in the trades are valuable due to the potential to reduce occupational injuries. The trades are male-dominated and have the highest rate of occupational injuries in Canada. Ely and Meyerson (2010) demonstrated that by addressing masculinity through specific organizational training, two offshore oil platforms were able to reduce their accident rates (by $84 \%$ ) and set new records for productivity, efficiency, and reliability. This type of training is atypical in male-dominated industries, yet demonstrates that addressing stereotypical masculine attitudes can reduce occupational injuries. Reducing occupational injuries within the population that currently has the highest rates of injury would positively impact the everyday lives of individuals, employers, and communities in Canada.

\section{Acknowledgments}

We wish to acknowledge and thank our supervising professor, Melanie Morrison, for her encouragement and guidance with this study. We would also like to thank our participants for completing our survey and sharing it with trades workers. Our friends and family were instrumental in distributing our survey on social media; we could not have completed our study without their support.

\section{References}

Addis, M. E., \& Mahalik, J. R. (2003). Men, masculinity, and the contexts of help seeking. American Psychologist, 58(1), 5. doi: 10.1037/0003-066x.58.1.5

Berdahl, J. L. (2007). Harassment based on sex: Protecting social status in the context of gender hierarchy. Academy of Management Review, 32(2), 641-658. doi: 10.5465/amr.2007.24351879

Breslin, F. C., Polzer, J., MacEachen, E., Morrongiello, B., \& Shannon, H. (2007). Workplace injury or "part of the job"? Towards a gendered understanding of injuries and complaints among young workers. Social Science \& Medicine, 64(4), 782-793. doi: 10.1016/j.socscimed.2006.10.024

Campbell, B., Schellenberg, E. G., \& Senn, C. Y. (1997). Evaluating measures of contemporary sexism. Psychology of Women Quarterly, 21(1), 89-102. doi: 10.1111/j.1471-6402.1997.tboo102.x

Courtenay, W. H. (2000). Constructions of masculinity and their influence on men's well-being: a theory of gender and health. Social Science \& Medicine, 50(10), 13851401. doi: 10.1016/So277-9536(99)00390-1

Denissen, A. M., \& Saguy, A. C. (2014). Gendered homophobia and the contradictions of workplace discrimination for women in the building trades.

Gender \& Society, 28(3), 381-403. doi: $10.1177 / 0891243213510781$

Ely, R. J., \& Meyerson, D. E. (2010). An organizational approach to undoing gender: The unlikely case of offshore oil platforms. Research in Organizational Behavior, 30, 3-34. doi: 10.1016/j.riob.2010.09.002

Ericksen, J. A., \& Schultheiss, D. E. P. (2009). Women pursuing careers in trades and construction. Journal of Career Development, 36(1), 68-89. doi: 10.1177/0894845309340797

Glick, P., \& Fiske, S. T. (2001). An ambivalent alliance: Hostile and benevolent sexism as complementary justifications for gender inequality. American Psychologist, 56(2), 109-118. doi: 10.1037/0003$066 \times .56 .2 .109$ 
Glick, P., Larsen, S., Johnson, C. \& Branstiter, H. (2005). Evaluation of sexy women in low and high status jobs. Psychology of Women Quarterly, 29, 713-728. doi:10.1111/j.1471-6402.2005.00238

Government of Canada. (2011). Work related injuries. Retrieved from Employment and Social Development of Canada website:

http://www4.hrsdc.gc.ca/.3ndic.1t.4r@-eng.jsp?iid=20

Hayes, B. E., Perander, J., Smecko, T., \& Trask, J. (1998). Measuring perceptions of workplace safety: Development and validation of the work safety scale. Journal of Safety Research, 29(3), 145-161. doi: 10.1016/Soo22-4375(98)00011-5

Levant, R. F., Hall, R. J., \& Rankin, T. J. (2013). Male Role Norms Inventory-Short Form (MRNI-SF): Development, confirmatory factor analytic investigation of structure, and measurement invariance across gender. Journal of Counseling Psychology, 6o(2), 228. doi: 10.1037/a0031545

Maclsaac, K. M., \& Domene, J. F. (2013). Learning the tricks of the trades: Women's experiences. Canadian Journal of Counselling and Psychotherapy/Revue Canadienne de Counseling et de Psychothérapie, 48(1). Retrieved from http://www.cjc-

rcc.ucalgary.ca.cyber.usask.ca/cjc/index.php/rcc/articl e/view/2502/2509

McDonald, J. (2012). Conforming to and resisting dominant gender norms: How male and female nursing students do and undo gender. Gender, Work \& Organization, 2o(5), 561-579. doi: 10.1111/j.1468-0432.2012.00604.x

Miller, D. T., \& McFarland, C. (1991). When social comparison goes awry: The case of pluralistic ignorance. In J. Suls \& T. A. Wills, (Eds.), Social Comparison: Contemporary Theory and Research (pp. 287-313). Hillsdale, NJ: Lawrence Erlbaum Associates, Inc.

Monin, B., \& Miller, D. T. (2001). Moral credentials and the expression of prejudice. Journal of Personality and Social Psychology, 81(1), 33. doi: 10.1037/00223514.81.1.33

Moss-Racusin, C. A., Dovidio, J. F., Brescoll, V. L., Graham, M. J., \& Handelsman, J. (2012). Science faculty's subtle gender biases favor male students. Proceedings of the National Academy of Sciences, 109, 16474-16479. doi: 10.1073/pnas.1211286109
Ness, K. (2012). Constructing masculinity in the building trades: Most jobs in the construction industry can be done by women. Gender, Work \& Organization, 19(6), 654-676. doi: 10.1111/j.1468-0432.2010.00551.x

Pfeifer, J. E., \& Ogloff, J. R. (2003). Mock juror ratings of guilt in Canada: Modern racism and ethnic heritage. Social Behavior and Personality: An International Journal, 31(3), 301-312. doi: 10.2224/sbp.2003.31.3.301

Prentice, D. A., \& Miller, D. T. (1993). Pluralistic ignorance and alcohol use on campus: some consequences of misperceiving the social norm. Journal of Personality and Social Psychology, 64(2), 243. doi: 10.1037/0022$3514 \cdot 64 \cdot 2.243$

Ray, W. J. (2011). Methods toward a science of behavior and experience. (1oth ed.) Chicago, IL: Cengage Learning.

Reskin, B. F., \& Bielby, D. D. (2005). A sociological perspective on gender and career outcomes. Journal of Economic Perspectives, 19(1), 71-86. doi: $10.1257 / 0895330053148010$

Statistics Canada. (2016). Employment, by industry and sex. Retrieved from http://www.statcan.gc.ca/tablestableaux/sum-som/lo1/csto1/labor1ob-eng.htm

Tougas, F., Brown, R., Beaton, A. M., \& Joly, S. (1995). Neosexism: Plus ca change, plus c'est pareil. Personality and Social Psychology Bulletin, 21, 842-849. doi: 10.1177/0146167295218007

Vogel, D. L., Heimerdinger-Edwards, S. R., Hammer, J. H., \& Hubbard, A. (2011). "Boys don't cry": Examination of the links between endorsement of masculine norms, self-stigma, and help-seeking attitudes for men from diverse backgrounds. Journal of Counseling Psychology, 58(3), 368. doi: 10.1037/aoo23688

Work Safe Alberta. (2012). Occupational injuries and diseases in Alberta: Lost-time claims, disabling injury claims, and claim rates, 2011 Summary. Retrieved from http://work.alberta.ca/documents/2011-OccupationalInjuries-Diseases-Alberta-Summary.pdf

WorkSafeBC. (2012). WorkSafeBC Statistics 2012. Retrieved from

http://worksafebc.com/publications/reports/statistics_ reports/assets/pdf/stats2012.pdf 
Masculine Attitudes in the Trades (Jaeb et al.)

University of Saskatchewan Undegraduate Research Journal 